\title{
THE EXTENDED DUAL-ASPECT MONISM FRAMEWORK: AN ATTEMPT TO SOLVE THE HARD PROBLEM
}

\author{
Ram Lakhan Pandey Vimal ${ }^{1}$
}

\begin{abstract}
In prior work, we reported the followings: (i) There are about forty meanings attributed to the term consciousness. They were identified and categorized according to whether they were principally about function or about experience. (ii) The frameworks for consciousness that are based on materialism, idealism, and dualism have serious problems. Therefore, an extended dual-aspect monism (eDAM) framework was proposed for consciousness, where (a) the problematic materialism/ panpsychism based integrated information theory (IIT) was interpreted and (b) the inseparability between physical and non-physical aspect holds because none of the empirical fMRI/EEG data shows separability between aspects. This has the least number of problems compared to all other frameworks. It required a novel feature that the potentiality of primary irreducible subjective experiences co-exists with its physical aspect in nature. This missing information in science is provided by the eDAM, which addresses the hard problem of consciousness successfully, which is elaborated in detail in this article.
\end{abstract}

KEYwords: Consciousness. Dual-aspect monism. Non-physical and physical aspects. Interdependent co-arising. Hard problem.

\section{InTRODUCTION}

We propose a five component extended version of dual-aspect monism (eDAM) metaphysics framework developed in five articles [(VIMAL, 2008, 2010a, 2013, 2015c, 2016b) and summarized in (VIMAL, 2016a) and (VIMAL, 2015c)], which attempts to address the hard problem of consciousness (CHALMERS, 1995). The least problematic eDAM is a monist framework, which is different from dualism and dual-aspect panpsychism. It is an alternative to a materialism based framework for consciousness (CRICK;

\footnotetext{
${ }^{1}$ Researcher at the Vision Research Institute, Lowell, MA - United States of America. E-mail: rlpvimal@yahoo.co.in

PhD, University of Illinois at Chicago. Post-Doc, University of Chicago and Schepens Eye Research Institute (Harvard Medical Schools).
}

http://dx.doi.org/10.1590/0101-3173.2018.v41esp.09.p153

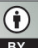

This is an open-access article distributed under the terms of the Creative Commons Attribution License. 
$\mathrm{KOCH}, 2003)$. Materialism does not address the hard problem because of the explanatory gap problem (Levine, 1983). Furthermore, Koch is sympathetic to a version of dual-aspect theory $(\mathrm{KOCH}, 2012)$ that involves problematic materialism-based integrated information theory (IIT) formulated by Tononi (TONONI, 2004, 2008, 2012). Tononi and Koch (TONONI; KOCH, 2014) are sympathetic to panpsychism that has serious problems (VIMAL, $2010 \mathrm{~b})$. These problems are addressed by interpreting the IIT in the eDAM as elaborated in (VIMAL, 2015c, 2019).

\subsection{HARD PROBLEM AND METAPHYSICS}

Chalmers (1995) categorized the problems into tractable problems of science as 'easy problems' ["how the brain generates the behavior associated with consciousness" (CERULLO, 2015)] and non-tractable problems of consciousness as 'hard problem' [how to explain the experiential aspect of consciousness or "why any physical process generates (or is) consciousness" (CERULLO, 2015)]. One could argue that 'functions and cognition' and experiences fall under easy and hard problems, respectively (COTTAM; RANSON, 2013; VIMAL, 2009a, 2010b). For addressing the hard problem, we need to start at foundational level (the root/metaphysics). There are four major groups of metaphysical frameworks: materialism, idealism, dualism, and dual-aspect monism. The first three metaphysics have serious problems as elaborated in Vimal (2010b, 2012b, 2013). The fourth metaphysics, the dual-aspect monism, has fewer problems compared to other metaphysics but is not well developed. Therefore, an extended version of dual-aspect monism (eDAM) metaphysics is proposed to address the 'hard' problem. The eDAM framework has five components which are elaborated in five articles (VIMAL, 2008, 2010a, 2013, 2015c, 2016b) and summarized in (VIMAL, 2016a); see also the e-books (VIMAL, 2012a, 2012b). The eDAM framework is also summarized (VIMAL, 2009b, 2015a, 2015b, 2016a; VIMAL; BHARDWAJ, 2015; VIMAL; BÓKKON; CSÁSZÁR; VAS; SZŐKE, 2015).

\subsection{THE FOUR MAJOR METAPHYSICS AND DEFINITION OF CONSCIOUSNESS}

\subsubsection{The FOUR METAPHYSICS}

This section is adapted from Vimal (2012b, 2013). An entity is a general term used for a substrate, a field, a particle, a wave, a fermion, a boson, a 
composite of fermions and bosons such as a classical object including a gene, a cell, a neuron, a neural-network (NN), a brain, a subject, a family, a society, a city, a country, the whole universe or anything. An entity has one or more states. One could categorize all the entities/properties of our universe into two groups: physical (P) entities/properties from the $3^{\text {rd }}$ person perspective (3pp) and nonphysical (NP) entities/properties from the $1^{\text {st }}$ person perspective (1pp). This categorization entails four major philosophical positions: (I) Materialism: NP from $\mathrm{P}$ (P is primitive/fundamental), which includes materialistic frameworks, such as the naturalistic/physicalistic/materialistic nondual monism, physicalism, materialism, reductionism, non-reductive physicalism, naturalism, or Cārvākal Lokāyata [800-500 BCE: (BHATTACHARYA, 2013; RAJU, 1985; SINGH, 2002; VIMAL, 2012b)]. (II) Idealism: P from NP (NP is primitive), which includes idealistic frameworks, such as the idealism, mentalistic nondual monism, or Advaita [non-dualism (Ādi Śankarāchārya, 788-820 AD) (RADHAKRISHNAN, 1960; VIMAL, 2012B)]. (IIIa) Cartesian interactive substance dualism: $P$ and NP substances are independent (from western perspective). However, they can interact (both P and NP substances are equally primitive) as in the interactive substance dualism (ISD). (IIIb) Sänkhya: The eastern non-interactive dualism metaphysics is called Sänikhya (1000-600 BCE or even before Gìta) or Gìta (3000 BCE) (VIMAL, 2012b) and (Radhakrishnan, 1960). Here, Prakrti and Purușa two independent fundamental primal entities; Purușa simply is an eyewitness type inactive/passive experiencer. It does not actively interact with Prakrti that has causal and astral bodies like a mind/ cognition and physical bodies like the matter. Purușa 'shines' the processes of Prakrti at Chitta (causal body) to experience it but does not interfere the process. If we compare with ISD, the ISD's NP can be further divided into three groups of entities: astral bodies $\mathrm{NP}_{\mathrm{a}}$, causal bodies $\mathrm{NP}_{c}$, and the experiencer $\mathrm{NP}_{e}$. The Prakrti (physical) is composed of $\mathrm{P}_{\mathrm{NP}}$ (astral but physical), and $\mathrm{NP}_{\mathrm{c}}$ (causal but physical), whereas Purusa is simply NP (non-physical). Thus, there are two kinds of dualism. (IV) The extended dual-aspect monism (eDAM): P and NP are two inseparable aspects of a state of an entity, which includes dualaspect monistic frameworks, such as the extended dual-aspect monism (eDAM, Dvi-Pakșa Advaita / द्विपक्षाद्वैत, or Ubhayādvaita / उभयाद्वैत). There are other aspect-monism frameworks, such as triple aspect monism at a conscious state (Pereira Jr., 2013; Pereira Jr., Vimal, \& Pregnolato, 2016), neutral monism Kashmir Shaivism (Vasugupta, 860-925 AD), and cit-acit Viśsistāodvaita [Ramānujāchārya, 1017-1137 AD: mind (cit) and matter (acit) are adjectives/ aspects of Brahman, see (Radhakrishnan, 1960; Vimal, 2012b)]. In triple aspect 
monism, $\mathrm{P}$ is physical aspect-1; NP can be further divided into non-conscious informational NP aspect-2 and conscious NP aspect-3. In terms of Nāgārjuna’s $\mathrm{IC}$ and inherent existence, in the eDAM, if the primitive/fundamental entity is the unified informational energy field (UIEF) at dual-aspect unmanifested state, then the IC suggests that UIEF at dual-aspect unmanifested state is the only primal entity-state that inherently exists and all other manifested dual-aspect states of all entities interdependently co-arise (VIMAL, 2018). The unmanifested state of UIEF has (a) universal potential consciousness informational energy field (UPCIEF) as non-physical aspect and (b) inseparable physical UIEF (PUIEF) as physical aspect. The first three (I-III) of the four groups of frameworks have serious problems as elaborated in Vimal (2010b, 2012b, 2013). The fourth metaphysics, the dual-aspect monism, has the least number of problems compared to other metaphysics, but not well developed. Therefore, an extended version of dual-aspect monism (eDAM) metaphysics is proposed that also addresses the 'hard' problem.

\subsubsection{Consciousness}

The optimal definition (that has the least number of problems) of consciousness is: Consciousness is the non-physical aspect of a beable ontological dual-aspect state of a mind-brain-system or a mind-brainprocess, which has four sub-aspects: a conscious experience (experiential sub-aspect), conscious cognition (cognitive sub-aspect), conscious qualities (patterns/forms: qualitative sub-aspect), and a conscious function (functional sub-aspect) from the $1^{\text {st }}$ person perspective (1pp); see also Vimal (2010b). The experiential sub-aspect includes (a) experiencer (SE related to self), (b) subjective experiences (SEs) of objects, emotions, and thoughts, and (c) Samädhi state SEs. This special beable ontological dual-aspect state has specific SE when 'viewed' from the 1pp and has its inseparable physical aspect (neuralphysical basis (NPB): correlated specific NN and its activities) when the same "effective" information is 'viewed' from the $3^{\text {rd }}$ person perspective (3pp).

\section{EXTENDED DUAL-ASPECT MONISM (EDAM)}

This section is adapted from (Vimal, 2017). The extended dual-aspect monism (eDAM, Dvi-Pakșa Advaita Vedānta) is a middle way (between materialism and idealism/dualism) framework. The eDAM is based on two 
sources of robust, highly reproducible, empirical data, which is called Baars' dual-source theory (DST); this is interpreted in terms of the eDAM. From the discussion with Baars (November 19-22, 2015), my working hypothesis evolved to be as follows: The "effective" information is the same in both (1pp and $3 \mathrm{pp}$ ) sources for the same conscious event within the critical spatiotemporalspectral interval threshold at a beable ontological (conscious) state of our mind-brain system. They appear different because perspectives (1pp and 3pp) of "viewing" are different. I assume that these two sources are two inseparable aspects of the same conscious state of the same mind-brain system to address from the association problem of separability in dualism. As per Crick and Koch, the hard problem of consciousness is the most difficult problem; it is "fruitless to approach this problem head-on"; instead, it will be useful first to find "the neural correlate(s) of consciousness (NCC)" and then try to explain it in causal terms; this will hopefully tell us how to address the hard problem (CRICK; KOCH, 2003). This strategy might have lead Koch towards a version of dual-aspect monism in $(\mathrm{KOCH}, 2012)$, but it certainly led me to the eDAM framework (section 2) that tries to solve the hard problem. The eDAM framework is consistent with psychophysical, biological, and physical laws and the principle of 'interdependent co-arising' (also called 'dependent co-origination'). This framework can be tested scientifically as elaborated in Vimal (2015c, section 3.2; 2019, section 3.5). For example, if the separability between the non-physical and physical aspects of a conscious brain-mind state is found under a single condition, the hypothesis of inseparability will be rejected; then the eDAM framework needs major modification.

\subsection{The POSTULATES OF THE EXTENDED DUAL-ASPECT MONISM (EDAM)}

\subsubsection{Definitions}

The physical attributes (properties) of an elementary particle (fermion or boson) are mass, charge, and spin, which are included in the physical aspect of a state of an entity. In other words, all 12 fermions, 5 bosons, and 1 hypothetical boson graviton are all elementary particles and hence they are all physical entities. The attributes that are not physical are categorized as non-physical attributes, which are included in the non-physical aspect of the same state of the same entity. There are four sub-aspects of both non-physical and inseparable physical aspects, namely, experiential, cognitive, qualitative, and functional sub-aspects. The non-physical properties are, for example, 
(a) subjective experiences (SEs: including affective emotions/feelings) and self (experiencer) as experiential sub-aspect of the non-physical aspect, (b) cognitive sub-aspect such as thoughts, attention, intention, and memory, (c) qualitative sub-aspect such as patterns/forms, and (d) functional sub-aspect such as functions (including enaction/action). The experiential, cognitive, and/or functional sub-aspects are also called "mental sub-aspect". Each of the sub-aspects of non-physical aspect has corresponding inseparable physical aspect. A dual-aspect quantum (template) state (also called wavefunction) of a quantum particle (such as an elementary particle) is composed of the superposition of all possible/potential innumerable beable ontic dual-aspect states as the basis states in the eDAM's Hilbert space. A specific beable ontic dual-aspect state is realized/actualized thru the collapse of these superposed dual-aspect states to it. The term 'latent' means unmanifested/hidden (not absent). For example, the experiential and cognitive sub-aspects of both aspects of a state of a stone are latent. However, if the elementary particles of a stone are re-organized (technically almost impossible) to human brain with the help of other elementary particles (that are not in the stone but necessary in the formation of a human brain), then those latent/unmanifested experiential and cognitive sub-aspects can be manifested. Presumably, the evolution has done this job, but it took over billions of years. Materialists might claim that these latent sub-aspects are absent in inert entities. However, if they were absent, how is it possible that we have them? Another way of thinking about "latent" is that an unmanifested state of an inert entity (similar to primal entity) is composed of the superposition of all possible/potential beable ontic states (other than the state that is already manifested) as basis states of the Hilbert space. When the necessary conditions for the co-manifestation of a beable ontic conscious state (for a specific experience or cognition) are satisfied then the physical and non-physical aspect related to experiential or cognitive subaspect will be co-manifested.

These definitions are only for the eDAM, i.e., when empirical subjective and objective data are interpreted in terms of the eDAM. It should be noted that all subjective and objectives data are based on our subjective experience (SEs), which are ineffable. When we use our own words during a speech or write them, they are nothing but our own interpretations based on our favorite framework. This is because all SEs are private and personal and are ineffable. We agree because we have the similar systems and we disagree if our systems are different. For example, trichromats will experience redness when they look at a ripe tomato, but achromats will not; instead, they 
experience dark grayness. Each of the four major groups of frameworks has its own definitions and postulates. We must not mix interpretations; otherwise, confusion will arise. For example, the eDAM categorizes patterns/forms and functions as non-physical aspects based on the above definitions (see below for further justification). However, Sānkhya and materialism consider them as a part of physical aspect. For Sānkhya, only the experiencer/Puruṣa is nonphysical separable aspect; for materialism there is no non-physical aspect, rather it arises from the physical aspect; for idealism, only non-physical aspect exists, matter is nothing but condensed/congealed consciousness (SEs). Some erroneously consider interpretations of ineffable SEs data as evidence. Furthermore, the eDAM uses 'interdependent co-arising') of aspects instead of causality. This is because entities lack inherent existence, which clearly shows that they (patterns/forms and functions) are not caused by and not created by the matter, and the eDAM can logically argue for these (qualitative and functional) sub-aspects being categorized in the non-physical aspect and each of them has corresponding inseparable physical aspect.

\subsubsection{Physical VS. NON-PHYSICAL}

What is physical? One could argue that the categorization of properties into physical and non-physical depends on a framework. Let us, consider the following properties of entities and their states: (a) mass, charge, and spin of fermions and bosons that constitute whole physical universe and (b) patterns/ forms, functions, cognition, and subjective experiences of objects, and (c) the self (SE of subject) as the experiencer. Let us examine how the four major groups of frameworks have categorized them. As per materialism, all properties (a) to (c) are physical. For Idealism, all (a) to (c) are non-physical. According to non-interactive dualistic Sānkhya, properties (a) and (b) are physical, whereas (c) is non-physical. Cartesian interactive substance dualism (ISD) postulates that properties in (a) are physical, whereas (b) and (c) are nonphysical, where separability holds. In the eDAM properties in (a) are included in the physical aspect and properties in (b) and (c) are incorporated in the non-physical aspect of a state of an entity; however, the inseparability holds to address the serious problem of association of dualism. It seems that the eDAM follows Cartesian ISD's classification (except inseparability between the two aspects) to honor some of the concepts of dualism towards bringing them (materialism, idealism, and dualism) closer. How do we decide which classification is preferred? For this purpose, we need to have some framework 
selection criteria. I propose the following criteria: (I) Occam razor parsimony, (II) the number of authentic problems, and (III) subjective and objective evidence based on empirical data. (I) Occam razor parsimony $=1 /$ (number of free parameters): $1: 1: 1: 0.5::$ materialism : idealism : eDAM : dualism. (II) Number of unresolvable authentic problems that have consensus: $1: 1: 0$ : 13 :: materialism : idealism : eDAM : dualism. (III) Subjective and objective evidence based on empirical data: all four groups of framework try to explain the empirical data in their own ways; it is unclear which explains the best. Therefore, it does not seem to be useful criterion. Therefore, based on (I) and (II), the eDAM should be the preferred framework. The eDAM is a middle way framework between materialism and idealism (the two opposite poles) and tries to make a bridge them. It tries to honor some of the concepts from other three groups of frameworks (idealism, materialism, and dualism). (IV) Model selection criterion (MSC) from Akaike information statistics (AIS): It leads to the same conclusion as Occam razor parsimony, which is elaborated in Vimal (2015a, section 2.3). In my discussion with John Jay Kineman (3 December 2018), he suggested six additional criteria for the framework selection: (V) Generality (explanatory power): Do the meta-theory or theory assumptions work everywhere in all situations? (VI) Consistency: Are the assumptions consistent with what we already know? (VII) Necessity: Do the new assumptions resolve a clearly established paradox in the old view? (VIII) Parsimony: Are the new assumptions the minimum required to allow theories based on them to explain more phenomena, more accurately, with less overall work? (IX) Formality: Can the meta-theory be formalized in mathematical terms? And (X) Productivity: Do the new assumptions lead to successful theory? The eDAM satisfies all the ten criteria. Therefore, it ranks with the best.

\subsubsection{INSEPARABILITY HYPOTHESIS}

We all are puzzled on how and where from a subjective experience (SE: SE of the subject as self or SE of objects) arise in our mundane conscious life. We can assume two possible primal sources: (i) cosmic consciousness (CC) in top-down approach (TDA) and (ii) universal potential consciousness informational energy field (UPCIEF) as non-physical aspect of the unmanifested state of unified informational energy field (UIEF) and Physical UIEF (quantum vacuum) as its inseparable physical aspect in the eDAM that follows bottom-up approach (BUA). Monistic Vedanta is underlying 
metaphysics for non-interactive dualistic Sankhya in TDA, which I do not follow because it leads to 13 unresolvable problems that have consensus for a long time (VIMAL, 2012b). Therefore, I will briefly discuss only BUAbased eDAM.

In the eDAM, the dual-aspect unmanifested state of the UIEF is composed of the superposition of innumerable possible/potential beable ontic states as basis state of Hilbert space. A specific beable ontic dual-aspect state (out of innumerable superposed states) is actualized/manifested when its necessary conditions are satisfied thru interdependent co-arising (IC). This means that it's both aspects also co-manifested. For example, let this specific state is the ground state of an electron. Then the mass, charge, and spin of the electron as its physical aspect and its function and pattern/form as its inseparable non-physical aspect are co-manifested. Similarly, we can argue for other 17 elementary particles (or more if new elementary particles are discovered). In other words, I have assumed that the 18 dual-aspect elementary particles are the necessary building blocks of the universe including us as science assumes. If in future, new elementary particles are discovered then we can easily include them. It should be noted that the eDAM has introduced the non-physical aspect in the current physics without violating it (VIMAL, 2010c, 2010d, 2010e). It is like re-arranging the attributes of elementary particles. The patterns/forms, as also the properties of elementary particles, are implicitly already present in terms of wave-particle duality and their respective functions for building their composites such as atoms, molecules, and classical objects in physics and living entities (including us) with cognition and experiences as new (non-physical) properties in neurobiology. However, what happens to other unmanifested innumerable superposed beable ontic states after the manifestation of all elementary particles? A short answer is they are in superposed form in each state of each elementary particle. This needs a little more unpacking.

Let us take an example of electrons. Electrons are in all NNs (such as related to vision, auditory, taste, smell, touch etc) and almost in all composite living and non-living entities. Therefore, it is easy to think that they contribute thru some physical and biological laws. For example, they are five sensory systems is us. Each sensory system [also called modes in the eDAM as in Vimal (2015c)] has many sub-systems (sub-modes) such as color, motion, shape etc in vision. Each sub-mode has many dimensions, such as red, green, blue etc for color sub-mode. Similarly, we can argue for the other 
elementary particles. Let us consider a redness-related beable ontic dual-aspect conscious state that has SE redness as experiential sub-aspect of non-physical aspect and redness-related V8-NN and its activities as its inseparable physical aspect. If the necessary conditions of this beable ontic state are satisfied, then it is manifested. When it is realized/manifested, it's both aspects are also comanifested thru IC. Why do we need the inseparability hypothesis? What is its purpose? Does it explain why SEs occur in the brain? Under what condition can we relax it? These queries are addressed as follows.

There is inseparability between physical and non-physical aspects. It has both subjective and objective pieces of evidence. For example, at wakeful conscious state, there are a large number of subjective (psychophysical) and objective (fMRI/EEG) reports that are consistent with inseparability between aspects because none of the reports show separability. It must be noted that science only rejects a hypothesis and does not prove it. Therefore, the inseparability hypothesis can be rejected only when experiments clearly show that aspects are separable. If separability is found in the experiments proposed in Vimal (2015c), then the monistic frameworks such as the eDAM will certainly be rejected. If the eDAM is understood correctly, both aspects of a beable ontic state of an entity always go together, i.e., both aspects must manifest simultaneously and equally and hence the inseparability between aspects are always maintained in all conditions and at all levels. If anyone finds a single case of clear-cut separability under a single condition at any level at any time at any location, then the eDAM will be rejected. This search for separability is a challenge to all researchers. The highest state of ineffable Samadhi SE has been interpreted by three of the six sub-schools of Vedanta that are consistent with a dual-aspect view. These three sub-schools of Vedanta are Cit(non-physical aspect)-acit(physical aspect) Visisistädvaita (qualified nondualism), Dvaitädvaita, and Achintya-Bheda-Abheda (inconceivable oneness and difference). In the eDAM framework, there is no separate sub-substrate of each aspect; physical aspect (or non-physical aspect) does not manifest from the physical aspect (or non-physical aspect) of its precursor. Instead, both aspects of a beable ontic state of an entity interdependently co-arise together simultaneously when the beable ontic state of the entity is actualized if all necessary conditions are satisfied for its co-arising. Similarly, if Sānkhya is interpreted in the eDAM framework, Purușa (or Prakṛti) does not have separate substrate in the formless, attributeless aspectless symmetric dual-aspect primal substrate Brahman or "unus mundus" ("nothingness"/"emptiness"). Instead, Puruṣa and Prakṛti inter-dependently co-arise from the Brahman 
simultaneously when all necessary conditions are satisfied for their co-arising. Here, "causality" is not used because IC (interdependent co-arising) here explains better in my view. In the eDAM, the Purușa and Prakrti are the inseparable non-physical and physical aspects of the unmanifested state of the primal entity Brahman.

\section{The JUSTIFICATIONS FOR THE INSEPARABILITY}

The ten justifications for the inseparability between non-physical and physical aspects are as follows: (i) It solves the serious unresolvable association problem of dualism, where the separability between the two aspects is postulated. (ii) There are robust and highly reproducible two sources (1pp and 3pp) of subjective and objective data, which support inseparability and rejects separability. (iii) The "effective" information is the same in both aspects. (iv) If we change the information in one aspect, the information in the other aspect also changes correspondingly. This implies a 1-1 relationship between aspects. (v) There is no evidence of separability between aspects in all empirical data. (vi) The ecosystem ecology also supports inseparability. (vii) It solves the hard problem of consciousness. (viii) It keeps the monism intact and hence increases the scientific viability of the framework on the top (100\%) thru Occam Razor Parsimony. (ix) The original source of a dual-aspect entity is the primal dual-aspect substrate/structure such as the unified informational energy field (UIEF). (x) The source of "effective" information is the stimulus: physical information of the stimulus is transformed into neural-physical information by the photoreceptors, retinal, LGN, and cortical neurons.

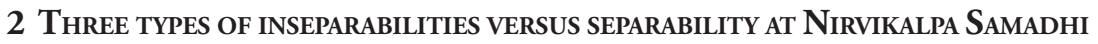 (NS) STATE}

An opponent's argument is that since yogis report very strong OBE ("real" OBE) at NS state, subject (self) is separable from its NCC/NPB and hence inseparability is untenable. This is called experiencer-related separability at NS or Mokshic/liberated state. This has nothing much to do with the objectrelated inseparability between non-physical aspect (SE) and physical aspect (it's NPB) of a conscious state of a mind-brain system. Let me clarify. There are three types of inseparabilities: 
(I) Subject-object inseparability: The separability of the subject (experiencer, self, individualized Purușa) and objects (related objectrepresentations in specific NN of the brain, Chitta/Prakrti) causes the association problem in Sänkhya-dualism and Cartesian-dualism. The inseparability between them is within a critical spatiotemporal-spectral interval to resolve the association problem. It must be noted that there is only one "self" in a mind-brain system, which needs to attend many tasks. Therefore, it should be separable after it attends a task, such as after matching and selection of a specific SE related to an object and experiencing it.

(II) Experiencer (subject's SE, self)-related non-physical and physical aspects inseparability: The inseparability is between self (SE of the subject: non-physical aspect) and it's NCC/NPB (cortical and subcortical midline structure: physical aspect). The argument that since at NS state yogis report very strong OBE ("real" OBE), subject (self) is separable from its correlated NCC/NPB). However, its NCC/NPB has never been measured using $\mathrm{fMRI} / \mathrm{EEG}$. Therefore, the experiencer-related separability is speculative until the experiment shown clear-cut separation.

(III) Object-related non-physical and physical aspects inseparability: The inseparability is between an SE of objects and it's NCC/ $\mathrm{NPB}$ (redness and related V8-NN and its activities). This is not relevant to the eye-closed meditation related SE-data.

\subsubsection{Four SUB-ASPECTS, INSEPARABILITY, AND DEGREE OF CO-MANIFESTATION OF ASPECTS}

There are at least four sub-aspects of each of the non-physical and physical aspects of a state of an entity related to (1) subjective experiences (SEs of subject (self) and objects, including affective emotions/feelings: SE of all types of sensation and emotions), (2) cognition (including knowing: logical-mathematical thinking, attention, learning, memory, planning, moral judgment, decision-making, and perception), (3) functions [including enaction/action: (PEREIRA JR., 2018, p. 212)], and (4) patterns/forms. In other words, the non-physical aspect has four sub-aspects: experiential/ affective, cognitive, functional/enactive/'action-related', and qualitative (patterns/forms) sub-aspects. Similarly, the physical aspect also has corresponding respective four sub-aspects related to respective neural-physical 
basis (NPB). There is no separate and independent mental or physical state; a state is always inseparable dual-aspect state.

For example, the redness-related beable ontic conscious dual-aspect state of a subject's mind-brain system has (i) a specific subjective experience (SE) redness as the experiential sub-aspect of the non-physical aspect from the subject's 1pp, and (ii) the redness-related NN and its activities (neuralphysical basis, NPB) as the experiential sub-aspect of the physical aspect from the subject's 3pp (but it is the $3^{\text {rd }}$ person-viewer's $1 \mathrm{pp}$ ). Similarly, we could argue for other three sub-aspects for this beable ontic state of the subject's mind-brain system. This beable ontic conscious state of the subject's mindbrain system has the full co-manifestation of each of all four pairs of subaspects. If we arbitrarily assign the degree of co-manifestation of a sub-aspect as $25 \%$, then the total will be $100 \%: 25 \%$ for experiential $+25 \%$ cognitive $+25 \%$ qualitative $+25 \%$ functional of each of both aspects, then the total will be $100 \%$ degree of co-manifestation of both aspects. In other words, the degree of manifestation of the non-physical aspect is $25 \%$ for SEs and that of the inseparable physical aspect is also 25\% for SEs; similar argument is applicable for other three sub-aspects. Thus, a specific sub-aspect of physical and non-physical aspects are equally co-manifested, which clarifies the inseparability of the aspects. However, this arbitrary method will raise a query: what is that beable ontic state which has $100 \%$ experience-related non-physical aspect and the related inseparable $100 \%$ physical aspect? Thus, this arbitrary method of assignment will create confusion. Therefore, we can try another method of assignment: assign $100 \%$ to this sub-aspect because it is indeed fully co-manifested beable ontic conscious state. If we do that then what is that beable ontic state that has the degree of co-manifestation of $25 \%$ or between 0 to $100 \%$ ? Can we assign $0 \%$ to deep sleep beable ontic state and $100 \%$ to the highest state of samādhi beable state? What would be degrees of co-manifestation of sub-aspects of both aspects of mokshic (liberated) state of a soul (if it really exists!). To answer these questions, we need to do careful calibration, need to attain all the seven (or more) states of consciousness, and need to measure them thru fMRI/EEG or more advance equipment, which clearly need further research.

Conceptually, there are four sub-aspects so divide 100 by 4, which is $25 \%$ for each sub-aspect. If only cognitive sub-aspect is co-manifested then it should have physical basis as well, which is $25 \%$ in both aspects compared to when all 4 sub-aspects are co-manifested $(100 \%)$ as in us in this wakeful 
conscious state. In other words, if only the experiential and cognitive subaspects are manifested then, the degree of manifestation of both sub-aspects of each aspect is $25+25=50 \%$ compared to when all four sub-aspects are manifested.

Similarly, the qualitative (patterns/forms) and functional sub-aspects of the non-physical aspect of a state of any entity should correspond to the qualitative and functional sub-aspects of the physical aspect of the same state of the same entity. For example, I can experience from my $1 \mathrm{pp}$ that I am raising my hand (that has pattern/form and function) to pick a cup of tea. If you look at it then you will also experience the same from my $3 \mathrm{pp}$, but it would be from your 1pp. In these cases, your and my observation would be the same for these two sub-aspects. Therefore, qualitative and functional sub-aspects can be grouped under both non-physical and physical aspects of a beable ontic state of my hand; this state has inseparable qualitative and functional sub-aspects of the physical aspect (NN and its activities). Again why? This is because of the definition and because of the observation from $1 \mathrm{pp}$ and from my 3pp (but from your 1pp) are the same. This is one of the reasons why qualitative and functional sub-aspects related to inert entities are grouped under the non-physical aspect of a beable ontic state of an inert entity, but this state also has qualitative and functional sub-aspects of physical aspect (material constituents are elementary particles; each of them has mass, charge, and spin) in the eDAM framework. This is how the eDAM maintains uniformity and consistency of inseparability and co-manifestation of both aspects together for all living and non-living/inert entities, which include the unmanifested state of the primal substrate thru extrapolation.

In other words, my hand has form/pattern and function. Thus, there are $1 \mathrm{pp}$-qualitative and $1 \mathrm{pp}$-functional sub-aspects of the non-physical aspect of a state of my hand. In addition, there are corresponding respective 3ppqualitative and 3pp-functional sub-aspects of the physical aspect of the same state of my hand as NPB from my 3pp. The patterns/forms (qualitative subaspect) and functions (functional sub-aspect) are usually on the surface of the entity (such as hand). They are usually invariant across subjects, i.e., I am raising/extending my hand to pick up a cup of tea; you see its patterns/ forms and functions or I see it; it would be the same. Of course, the patterns/ forms of the hand of each subject mostly will be different; for example, the fingerprint of an individual is unique. There is very little chance of making any error. It is because of this property and their definition, I have categorized 
them also under 1pp-non-physical aspect even though we would never know the $1 \mathrm{pp}$ of an entity (such as other's hand or stone).

Similarly, we can explain for the cognitive sub-aspect (such as thinking, decision-making, attention etc) of both aspects of a beable conscious state of a mind-brain system.

Some readers get confused between aspects and perspectives. Aspects are for a state of an entity and perspectives are for the self (subject)'s point of view looking the same "effective information. I have my neural-network and its activities inside my brain, which I cannot see them and it is physical; this is what I mean by from my 3pp; fMRI and EEG can record them (no need for you to see it from your 1pp). Of course, when you see the fMRI/ EEG analyzed data using some software then it would always be your 1pp. We all experience from our $1 \mathrm{pp}$, that is why the SE is private, personal, and ineffable. However, $1 \mathrm{pp}$ and $3 \mathrm{pp}$ data look entirely different when we look at for example a ripe tomato: 1pp-data is SE redness, but 3pp-data is grey and white color grey and white matter of $\mathrm{NN}$ and activities are neural signals (electrochemical) and physical signals such as hydro-ionic waves; there is no redness in 3pp-data. The mind-body problem is to find the relationship between two entirely different looking $1 \mathrm{pp}$ and $3 \mathrm{pp}$ experiential data. In other words, the eDAM will argue that there are four sub-aspects of the non-physical aspect and respective inseparable four sub-aspects of the physical aspect of a state of an entity.

Let us take another example of an inert entity such as a stone. Why do the states of inert entities not show experiential and cognitive sub-aspects of the non-physical aspect? This is because the corresponding experiential and cognitive sub-aspects of the physical aspect of the same state of the same inert entity are not manifested. Why? This is because beable ontic states of inert entities do not have them (absent vs. latent). Why? This is because their (experiences and cognition related) necessary conditions are not satisfied. This does not mean that inseparability is rejected. Why? This is because they have qualitative and functional sub-aspects; physical and non-physical aspects related to each of them are co-manifested in the beable ontic states of inert entities such as a stone. In other words, a stone has qualitative and functional sub-aspects, but its experiential and cognitive sub-aspects are unmanifested (latent: see the explanation in section 2.1.1). Therefore, the degree of comanifestation of both sub-aspects of each aspect is $25+25=50 \%$ compared to when all four sub-aspects are manifested as in the wakeful conscious state. If a 
conscious robot is able to satisfy the necessary conditions of experiences, then it will be robotic type experiences.

In other words, in the beable ontic states of inert entities (such as a stone), the qualitative and functional sub-aspects of the non-physical aspects are manifested because their necessary conditions are satisfied. However, experiential and cognitive sub-aspects are latent/hidden/unmanifested because their necessary conditions are NOT satisfied. In all beable ontic states of all entities, both non-physical and physical aspects are always present inseparably in a co-manifested or unmanifested (latent) form. In other words, the qualitative sub-aspect of non-physical aspect and the related the qualitative sub-aspect of the physical aspect of a state of an inert entity is co-manifested together. The experiential sub-aspect of non-physical aspect and the related the experiential sub-aspect of the physical aspect of a state of an inert entity is still unmanifested (latent). Similarly, we can examine the inseparability for other sub-aspects.

To sum up, the inseparability is not violated at any level. Therefore, co-ness (co-manifestation, manifestation together) and inseparability is always maintained. To sum up, there are four sub-aspects of (or related to) each of the physical and non-physical aspects of a state of an entity: experiential, cognitive, qualitative (patterns/forms), and functional sub-aspects. We can re-write the above as the physical aspect has four sub-aspects and the nonphysical aspect has the same respective four sub-aspects. This makes four pairs for each of the four sub-aspects): (i) Experiential sub-aspect: the inseparability is between (a) non-physical aspect (such as redness) for a subjective experience (SE) and (b) physical aspect (such as redness-related V8-NN) for the same SE. (ii) Cognitive sub-aspect: the inseparability is between (a) non-physical aspect (such as a thought) for a cognitive element and (b) physical aspect (such as thought-related NN) for the same cognitive element. (iii) Qualitative sub-aspect: the inseparability is between (a) non-physical aspect (such as a pattern/form) for a statue and (b) physical aspect (such as material clay) for the same statue. (iv) Functional sub-aspect: the inseparability is between (a) non-physical aspect (such as a function) for a statue and (b) physical aspect (such as material clay) for the same statue. 


\subsection{The EDAM FRAMEWORK HAS FIVE COMPONENTS}

(I) Dual-aspect monism framework: Here, each entity-state has inseparable 3pp-physical aspect and $1 \mathrm{pp}$ non-physical aspect. The qualitative and functional sub-aspects are for both non-living and living systems. The experiential and cognitive sub-aspects are for conscious living systems. The potentiality of primary irreducible subjective experiences (SEs) co-exists with its neural-physical basis (NPB) in Nature (VIMAL, 2008). (II) The matching and selection mechanism with dual-mode: The conjugate matching is between stimulus-dependent (or endogenous) feed-forward-signals-relatedmode and cognitive-feedback-signals-related-mode. After successful matching, the self selects a specific SE and experiences it; otherwise, the stimulus is a novel object and its related beable ontic state is selected and a related engram is created if it is a salient stimulus and is stored in the long-term memory; self experiences the related SE (VIMAL, 2010a). (III) Varying degrees of comanifestation (appearance/strength) of sub-aspects depending on the levels of entities and contexts: in all cases both related aspects are interdependently co-arise simultaneously (VIMAL, 2013). (IV) Segregation and integration of the "effective" information that is the same between two aspects: this is developed in Vimal (2015c, 2019). (V) Necessary conditions of consciousness, such as neural-network, wakefulness, reentry, attention, working memory and so on are developed in Vimal (2016b).

\section{AN ATTEMPT TO SOLVE THE HARD PROBLEM OF CONSCIOUSNESS}

The hard problem of consciousness is: how experiences arise and how the explanatory gap between 1pp non-physical aspect (such as a subjective experience) and 3pp-physical aspect (such as related NCC/NPB) can be closed. There are four major metaphysics to address this problem: (i) The materialism-based frameworks have been trying hard to address this issue but have failed. It cannot address the hard problem of consciousness because matter does not even have potential for experiences, by definition, as elaborated later. (ii) The idealism-based framework can solve this problem because it hypothesizes that experiences 'really' pre-exist (Kastrup, 2016). However, it has its own explanatory gap problem: how physical-neural-substrate-in-itself can be created from the related experience. (iii) The interactive substance dualism can address the explanatory gap because it also hypothesizes that experiences 'really' pre-exist. However, it has serious problems, such as 
how to associate a specific experience with the specific neural-network in addition to 12 more problems (VIMAL, 2012b). The problems of these three metaphysics are also elaborated in Vimal (2010b, 2013). (iv) The least problematic metaphysics is the $e D A M$ framework. It can also solve the hard problem because it hypothesizes that experiences 'potentially' co-exist with its neural-physical basis (NPB) in Nature.

The panpsychism framework proposes that all entities have mind/ consciousness to some extent. In general, there are panpsychists with dualaspect view (SKRBINA, 2009), panpsychist dualists, idealists, reductive materialists, and so on (SKRBINA, 2005). However, panpsychism has serious problems, such as the combination problem as elaborated in Vimal (2010b, 2013).

The solution of the hard problem is further elaborated as follows: To address the hard problem of consciousness, we first need to understand the concept of matter (entity), which has two different meanings (personal communication with Pereira Jr.) as follows. (i) The concept of Democritus (c.460-370 BC), who identifies matter with atoms (particles), and (ii) the concept of Aristotle (384-322 BC) for whom matter is "possibility of being" (Pereira Jr., 2013), which also includes 'form/pattern'. These two western concepts of an entity seem close to that of eastern system: (i) Cärvāka system and Kaṇāda's atomism (c. 800-600 BC), and (ii) Yājñavalkya's 'rūpa' (form/pattern) (c. 1000-700 BC) in Bṛhadäraṇyaka Upanișad (SWAMI KRISHNANANDA, 1983), and Bādarāyaña's 'rūpa' (form/pattern) (c. 500400 BC) in Brahma Sütra (RADHAKRISHNAN, 1960), respectively.

In Aristotle's framework, matter (material cause) alone does not explain the becoming process of reality; the efficient, formal and final causes are also needed. Natural beings (substances) are composed of matter and form/pattern (qualitative sub-aspect). The interactions of form/pattern and matter are central to the understanding of natural beings. In modern science (such as physics, chemistry and biology), the formal and final causes were abandoned. Therefore, the understanding of physical systems was reduced to the actions of efficient and material causes. This implies "matter" in the sense of Democritus. Here, the matter is defined as particles; they aggregate and recombine according to their actual properties. This is where matter was assumed as non-experiential entity, which does not even have potential for experience. This metaphysical view is called materialism that was adapted by science and end up with the hard 
problem of consciousness: how can experiences arise from non-experiential matter that does not even have a single trace of an experience?

In an Aristotelian perspective, there is no "pure matter"; all matter has embedded potential forms/patterns. This concept seems consistent with the quantum concept of superposition: what are superposed in a quantum state are states related to potential forms/patterns that can be actualized once the adequate conditions are satisfied in the previous state of the system as happens after measurement (this is Bohr's interpretation of QM).

The eDAM framework (section 2) and triple aspect monism (TAM) framework (PEREIRA JR., 2013) are close to Aristotelian perspective and Yājñavalkya-Bādarāyaņa’s 'rūpa' (form/pattern); 'rūpa' is in the sense that potentialities of subjective experiences exist in Nature. The eDAM is also close to cit-acit Visișțädvaita and Kashmir Shaivism (VIMAL, 2012b, 2013), where the primal entity is called Brahman with dual-aspect states, but are based on the top-down approach (TDA) from the manifested cosmic consciousness to universe that includes us.

One of the key features of the eDAM framework is that subjective experiences (SEs) potentially co-exist with their respective neural-physical bases (NPBs) in the related entity-states in Nature. This is in analogy to a tree potentially exist in its seed in nature (VIMAL, 2013). In other words, a specific SE (experiential non-physical aspect) potentially co-exists with its inseparable neural-physical basis (physical aspect) in a beable ontic state of a mind-brain system. This type of beable ontic states acts like basis states in the Hilbert space. A non-conscious state of an entity consists of the superposition of all potential basis states. If all the necessary conditions of a specific $\mathrm{SE}$ are satisfied (VIMAL, 2016b) then this potential SE is realized/actualized/manifested.

The materialism based frameworks, unfortunately, do not have this essential and natural key feature built-in from the dawn of physics, chemistry, and biology because of the Kanāa-Democritus' definition of materialism (matter is non-experiential entity and does not even have potential for experiences), and this is one of the main reasons, why materialism based frameworks cannot solve the hard problem.

Critiques could argue that abandoning formal and final causes by science is a good feature because presumably they can emerge from material and efficient causes (but how is unknown) so the redundancy is minimized to observe Occam razor. However, we also know that an entity has a form or 
pattern, which when present makes matter into a particular type of thing. Therefore, one could argue that natural science should explicitly reconsider formal cause. Furthermore, we know that we have experiences. Therefore, in the eDAM framework, it is natural to accept that matter has potential for experiences because we are one of the biological products of evolution and natural selection. Thus, the eDAM framework cannot fail because there could be a physics of consciousness with the assumption that matter has potential for experiences. We have shown that physics is invariant if we introduce mental (experiential, cognitive, and/or functional) sub-aspect of the non-physical aspect of a state of an entity (VIMAL, 2008, 2009c, 2009d, 2010a, 2010c, 2010d, 2010e).

Biology, unfortunately, was developed without this key feature and was based on this problematic materialism. Here, the origin of the problem was Kanāda-Democritus' definition of matter that does not have potential for experiences. Instead, we must use the alternative definition of matter proposed by Yājñavalkya-Bādarāyaṇa-Aristotle that includes rūpa/form and has potential for experiences. It is essential that we as biologists must instill this essential feature in biology if we want to solve the hard problem from the biological point of view. This does not violate any biological or physical law.

In other words, the hard problem of consciousness is: how experiences arise, i.e., how to explain the experiential aspect of consciousness. An attempt towards the solution for this hard problem needs all five components of the eDAM framework (section 2). This challenge can be met through the selection of a specific SE (let us take an example of redness), after the completion of matching/non-matching process as follows:

(I) The color-related long-term memory stores all possible (potential) color-related beable ontic dual-aspect states of the color-related neuralnetwork of a mind-brain system in superposed form as engrams or memory traces. Each of these states has 1pp non-physical and inseparable 3pp physical aspect. Each aspect has four sub-aspects: experiential, cognitive, qualitative, and functional sub-aspects as elaborated in section 2.1.4. The experiential sub-aspect of the non-physical aspect has color SEs such as redness.

(II) The interaction of 'long wavelength light'-stimulus dependent feed-forward (FF) signal and cognitive feedback (FB) signals in the 'V8/V4/ $\mathrm{VO}$ ' red-green color neural-network creates a specific beable ontic neural- 
network state after the completion of the matching/non-matching and selection processes as elaborated below in step (VI).

(III) This specific beable ontic state as a basis state is assigned to a specific SE, redness, and is included in the abstract Hilbert space 'during' neural Darwinism (EDELMAN, 1993). The neural Darwinism includes coevolution, co-development and sensorimotor co-tuning by the evolutionary process of adaptation and natural selection.

(IV) The specific SE, redness, is embedded as a memory trace (engram) in the 'V8/V4/VO' red-green color neural-network.

(V) Similarly, all SEs are embedded in appropriate neural-networks and their states are included in the Hilbert space as basis states.

(VI) When, for example, a specific redness-related stimulus (such as long wavelength light) is presented to our visual system, information is irreducibly integrated (VIMAL, 2015c) through: (a) The matching/non-matching brain process (VIMAL, 2010a) such as the interaction of the stimulus dependent feed-forward (FF) with feedback (FB) signals in the thalamocortical 'V8/V4/ VO' red-green color neural-network, and (b) The selection brain process in which the associated specific SE, such as redness, is selected by the self after the completion of matching/non-matching process that requires comparing the FF signal with memory-engram related FB signals. The self is a part of the feedback system. A large amount of dual-aspect information is generated to reduce the uncertainty during the selection (a brain process) of a specific conscious SE. The selection is out of all possible potential SEs embedded as memory engrams in the related neural-network by ruling out alternative potential SEs. This large amount of information is irreducibly integrated (VIMAL, 2015c). We do not consciously compare all (innumerable) possible SEs. Is this done non-consciously? This is highly unlikely because it is also a very time consuming Herculean task. The co-evolution and co-developmental processes (neural Darwinism) have already done this time consuming task during the formation of a specific neural-network (NN). For example, the formation of red-green channel related $\mathrm{NN}$ leads to a smaller repertoire of states for colors that have just noticeable differences (JND) between redness to greenness embedded in this specific NN as color-related engrams. Therefore, the comparison between stimulus-dependent feed-forward signals with this small repertoire in feedback system during matching is a feasible faster task and can be done non-consciously. When a specific SE is selected then consciousness 
arises. Similarly, we can argue for the whole unified consciousness, which will require the unification of experiences related to modes, submodes, and dimensions. Thus, the processes related to the information generation can be divided in two groups: (a) the co-evolution and co-development timeconsuming processes, and (b) the faster matching and selection processes.

(VII) The degree d of the co-manifestation (appearance/strength) of the mental sub-aspect (consists of experiential, cognitive, and/or functional sub-aspects) of the non-physical aspect with the related inseparable physical aspect of the state of the mind-brain system is proportional to the degree of integrated information $(\Phi)$. In other words, if the degree (or amount) of integrated information $(\Phi)$ is higher than the critical threshold for consciousness (VIMAL, 2015c), the degree d is also higher than its critical threshold for a specific $S E$. The degree d also represents the degree of specificity of SE. When d $=100 \%$, the selection of a specific SE is completed. Then this specific SE redness is experienced by the 'self' (VIMAL, 2010a).

Furthermore, as elaborated in Vimal (2015c), the repertoire of possible causal effects of the A on B and of the B on A is related to IIT's causerepertoire/effect-repertoire. It is measured by the effective information (EI) between $A$ and $B$. The value of EI for their minimum information bipartition is the integrated information $\Phi(S)$ for subset S. In other words, $\Phi(S)$ is the degree/amount of integrated information. Moreover, the cause-repertoire/ effect-repertoire of IIT is related to the degree of integrated information $(\Phi)$. Therefore, $\Phi(S)$ is related to the degree d of the manifestation of the mental sub-aspect of the brain-mind state.

The generation of specificity involved in premises (II)-(VI) is further unpacked using neural Darwinism (EDELMAN, 1993). The development of specificity of a SE in a specific neural network (such as color in V8/V4/VO area) is detailed in Vimal, (2008).

Furthermore, how quantum-superposition relates to qualia (SEs) and the specific and unified experience needs further clarification, which is as follows: (i) Primary experiences are fundamental and irreducible; they are not derived mental entities. (ii) For example, in color vision, there are 3 primary color experiences (redness, greenness, and blueness). Other colors are mixtures of these 3 primary colors with appropriate proportions (VIMAL; POKORNY; SMITH, 1987). (iii) The basis-states related to potential primary irreducible SEs are superposed in a state of each entity. (iv) For example, 
the subjective experience 'redness' is a primary color experience that cannot be reduced further. Therefore, the related state is called 'redness' basis-state, similarly for other experiences. (v) These experiences, when unrealized, are in potential form. Therefore, they can be called proto-experiences (precursor of $\mathrm{SE}$ ). (vi) In the superposed form of many basis-states, it is impossible to have a specific SE. The SEs will all be 'blurry'/vague in superposed form and will not be crisp/specific (PERLOVSKY, 2009). (vii) We need brain with complex adaptive neural-networks (such as thalamocortical reentrant network) that can have high degree of integrated information $(\Phi)$. In addition, all the necessary conditions of consciousness need to be satisfied (VIMAL, 2016b). (viii) Then, the matching/non-matching and selection mechanisms (VIMAL, 2010a) of the eDAM framework will facilitate in collapsing these potentially superposed basis-states into a specific basis-state related to a specific primary $\mathrm{SE}$ (such as redness) for its realization (actualization) as a specific beable ontic state. (ix) Once this is accomplished, the self-related signals (from corticalmidline-structures) interact with stimulus-related feed-forward signals and related cognitive feedback signals. This will then let the self to select and experience this specific experience 'redness'. (x) For non-primary SEs, such as binary purpleness (mixture of blueness and redness), extra processing is needed for integrated information related to color mixture. However, a specific experience 'purpleness' must be selected by matching/non-matching mechanism before it can be experienced. This is an explanation for (a) the dimensional (redness, blueness) feature integration and (b) the experience of redness or purpleness. (xi) We also need integrated information for sub-modal (such as color, motion, shape), modal (such as visual, auditory), spatial (such as the whole visual spatial field), and temporal (such as critical temporal grainsize $\Delta t$ ) attributes to have the experience of unified SE such as that of crowded downtown market.

Moreover, a subtle issue needs further clarification: (i) what is superposed? A state related to the 'element of a conscious experience' (PEREIRA JR., 2013) is a basis-state. These basis-states are the states that are superposed in the state related to the mental sub-aspect of non-physical aspect of a state of an entity. (ii) A basis-state related to a proto-experience/ feeling is a precursor of a basis-state related to the actuall real subjective experience itself. This is because an experience requires the experiencer and the experienced object. (iii) This needs the formation of neural-networks and fulfillment of other necessary conditions of consciousness (VIMAL, 2016b). (iv) These conditions are missing in an inert system unless conscious robots 
are developed. (v) A state related to the 'element of the experiencer' is a basisstate related to proto-self, core self, autobiographical self, and/or the passive invariant self (PIS, the aspect of the self that remains unchanged lifelong). (vi) A state related to the elements of the experienced object is a basis-state related to proto-cognitions, as in the case of the property of red. (vii) These basis-states (i.e., the states related to the 'element of the experiencer' and the 'elements of the experienced object') are also superposed in that state. (viii) They are actualized at the moment of experience forming episodes. (ix) What is conscious is always an episode composed of a collection of these elements (subjective and objective). An experience is an episode where "red" features as one of the proprieties that is instantiated (PEREIRA JR., 2013).

\section{Summary}

1. We summarize the matching and selection process as follows: (i) The basis-states related to potential primary irreducible subjective experiences (SEs) are superposed in a state of neural-network. (ii) The superposed basis-states collapse/reduce to a specific basis-state related to a specific primary SE (such as redness) for its realization (actualization). (iii) This realization is through the matching/non-matching and selection processes. The non-matching implies a novel stimulus with a beable ontic state, which is selected and experienced. If this is a salient stimulus, an engram is generated as a long-term memory trace for future encounter and matching. (iv) A specific SE is selected by the self (not by any homunculus). (v) The selection is accomplished when the integrated information $(\Phi)$ (BALDUZZI; TONONI, 2009; TONONI, $2004,2008,2012$ ) is higher than its critical threshold value for consciousness in the related neural-network 'complex' (VIMAL, 2015c).

2. The eDAM postulates that fundamental substrate is the formless, attributeless, aspectless, symmetric dual-aspect primal substrate or 'unus mundus' (many names such as Brahman, nothingness, emptiness, or unified informational energy field, UIEF). This aspectless 'unus mundus' (primal entity) is symmetric with respect to the physical and non-physical aspects of a state of an entity, i.e., the aspects are latent in the unmanifested state of the primal entity. This symmetry needs to be broken for aspects to interdependently co-arise thru the interaction among eternal random quantum fluctuations (QFs) in PUIEF (physical aspect) and consciousness fluctuations (CFs) in UPCIEF (non-physical aspect) that generates enough "pressure" to break the 
symmetry via Cosmic Fire (Big Bang), which is consistent with Brihadāraṇaka Upanișad’s cosmology (VIMAL, 2012b).

3. In all cases, the inseparability between aspects is maintained; so far, it has never been violated. If one, more or all of the four sub-aspects of inseparable aspects are manifested, the co-manifestation and inseparability are still maintained for each of the respective sub-aspect of non-physical and physical aspects. Thus, there is no intrinsic contradiction between eDAM's postulates if understood correctly. The concepts of uniformity and consistency throughout across all levels, all conditions, and all contexts are essential for a viable framework, which must not change according to their own convenience; otherwise, contradiction and problems will arise. For example, some models change from monism to dualism because the subject-object division is abolished at the highest state of samādhi whereas this division is essential to survive at the mundane level. The eDAM explains nicely this fact without violating monism because inseparability/monism is specific to a state of an entity.

4. If the eDAM is understood correctly, both aspects of a beable ontic state of an entity always go together, i.e., the co-ness (co-manifestation) and the inseparability between aspects are always maintained in all conditions and at all levels. If anyone finds a single case of clear-cut separability under a single condition at any level at any time at any location, then the eDAM will be rejected. This search for separability is a challenge to all researchers.

5. The eDAM does not break any existing laws of physics; it simply extends the physics. In other words, the physical aspect (such as mass, charge, and spin of elementary particles, which are the constituents of our physical universe) of a state of an entity is already well developed in physics. The eDAM adds the inseparable non-physical aspect to the same state of the entity. Therefore, energy conservation law is preserved in the eDAM.

6. If we can find a single case of clear-cut separability under any condition at any level at any time at any location, then the eDAM will be significantly modified.

7. The eDAM is a scientifically testable framework as proposed in Vimal (2015c, section 3.2; 2019, section 3.5). So far, 100s of fMRI/EEG reports do not find any separability between aspects and hence consistent with the eDAM. As we know, science does not prove any hypothesis, it only rejects if it finds any contradiction. 
8. In inert entities, obtaining evidence for the latent mental (experiential, cognitive, and/or functional) sub-aspects of the non-physical aspect is NOT necessary to test the eDAM. It is more efficient and useful to understand that qualitative and functional sub-aspects of the non-physical aspect of a state of an inert entity exist and explicitly has more than enough evidence in our mundane life. Thus, the non-physical aspect is well established in both living and non-living entities and is inseparable from the related physical aspect. The major obstacle in understanding this fact may be the view that they are created by the structure as in materialism or Prakṛti part of Sānkhya. Well, opponents can argue for this view and is fine with me. However, the main problem is as follows: are we going to accept materialism, dualism (ISD and Sānkhya), and idealism if we clearly understand that all these have serious unresolvable problems that have consensus over many years? Alternatively, should we prefer to consider the eDAM that has no such problems? ${ }^{2}$

VIMAL, R. L. P. A abordagem do monismo de duplo aspecto estendido: uma tentativa de resolver o problema difícil. Trans/Form/Ação, Marília, v. 41, p. 153-182, 2018. Edição Especial.

Resumo: Em trabalho anterior, relatamos o seguinte: (i) existem cerca de quarenta significados atribuídos ao termo consciência; eles foram identificados e categorizados conforme se referiam à função ou à experiência; (ii) as abordagens da consciência baseadas no materialismo, idealismo e dualismo têm sérios problemas. Por conseguinte, a abordagem do monismo de duplo aspecto estendido (eDAM) foi proposta para a consciência, em que: (a) a problemática teoria da informação integrada (IIT), baseada no materialismo/pampsiquismo, foi interpretada; e (b) se afirma a inseparabilidade entre aspectos físicos e não físicos, pois os dados empíricos das imagens por ressonância magnética funcional (fMRI) e eletroencefalografia (EEG) não mostram dissociação entre os aspectos. O eDAM tem o menor número de problemas, em comparaçấo com todas as outras abordagens, implicando que a potencialidade das experiências subjetivas, irredutíveis e primárias, coexiste com o seu aspecto físico na natureza. Esta informaçáo, ausente na ciência, é fornecida pelo eDAM, que aborda com êxito o problema difícil da consciência, o que é elaborado em detalhe neste artigo.

${ }^{2}$ Acknowledgments: Author would like to thank anonymous reviewers, Alfredo Pereira Jr., John Jay Kineman, and Vinod Kumar Sehgal for critical comments, discussion, and suggestions. Author is also affiliated with Dristi Anusandhana Sansthana, A-60 Umed Park, Sola Road, Ahmedabad-61, Gujrat, India; Dristi Anusandhana Sansthana, c/o NiceTech Computer Education Institute, Pendra, Bilaspur, C.G. 495119, India; and Dristi Anusandhana Sansthana, Sai Niwas, East of Hanuman Mandir, Betiahata, Gorakhpur, U.P. 273001 India. The regular update of this article is available in Vimal (2015c). URL: http://sites.google.com/site/rlpvimal/Home 
Palavras-chave: Consciência. Monismo de duplo aspecto. Aspectos físico e não físico. Co-originação interdependente. Problema difícil da consciência.

\section{REFERENCES}

BALDUZZI, D.; TONONI, G. Qualia: the geometry of integrated information. PLoS Comput Biol, v. 5, n. 8, 2009. doi: 10.1371/journal.pcbi.1000462.

BHATTACHARYA, R. Development of materialism in India: the pre-Cārvākas and the Cārvākas. Esercizi Filosofici, v. 8, p. 1-12, 2013. Available on: <http://www2.units.it/ eserfilo/art813/bhattacharya813.pdf >. Access in: 18 ago. 2018.

CERULLO, M. A. The problem with Phi: a critique of integrated information theory. PLoS Comput Biol, v. 11, n.9, 2015. https://doi.org/10.1371/journal.pcbi.1004286. Available on: <https://journals.plos.org/ploscompbiol/article?id=10.1371/journal. pcbi.1004286>. Access in: 18 ago. 2018.

CHALMERS, D. J. Facing up to the problem of consciousness. J Consciousness Stud. v. 2, n. 3, p. 200-219, 1995. Available on: <http://consc.net/papers/facing.html>. Access in: 18 ago. 2018.

COTTAM, R.; RANSON, W. A biosemiotic view on consciousness derived from system hierarchy. In: PEREIRA JR. A.; LEHMANN, D. (ed.). The unity of mind, brain and world: current perspectives on a science of consciousnes. Cambridge, UK: Cambridge University Press, 2013. p. 77-112.

CRICK, F.; KOCH, C. A framework for consciousness. Nat Neurosci., v. 6, n. 2, p. 119126, 2003.

EDELMAN, G. M. Neural Darwinism: selection and reentrant signaling in higher brain function. Neuron, v. 10, n. 2, p. 115-125, 1993.

KASTRUP, B. The idealist view of consciousness after death. Journal of Consciousness Exploration \& Research, v. 7, n. 11, p. 900-909, 2016. Available on: <http://jcer.com/ index.php/jcj/article/download/617/630>. Access in: 18 ago. 2018.

$\mathrm{KOCH}, \mathrm{C}$. Consciousness: confessions of a romantic reductionist. Cambridge, MA: The Massachusetts Institute of Technology (MIT) Press, 2012.

LEVINE, J. Materialism and qualia: the explanatory gap. Pac Philos Quart, v. 64, p. 354$361,1983$.

PEREIRA JR., A. Triple-aspect monism: a conceptual framework for the science of human consciousness. In: PEREIRA JR., A.; LEHMANN, D. (ed.). The unity of mind, brain and world: current perspectives on a science of consciousness. Cambridge, UK: Cambridge University Press, 2013. p. 299-337.

. The projective theory of consciousness: from neuroscience to philosophical psychology. Trans/Form/Ação, v. 41, n. especial, 2018, p. 199-232. 
. ; VIMAL, R. L. P.; PREGNOLATO, M. Can qualitative biophysics solve the hard problem? In: POZNANSKI, R. R.; TUSZYNSKI, J. A.; FEINBERG, E. T. (ed.). Biophysics of consciousness: a foundational approach. Singapore: World Scientific, 2016. p. 149-188.

PERLOVSKY, L. I. Vague-to-crisp neural mechanism of perception. IEEE Trans Neural Netw, v. 20, n. 8, p. 1363-1367, 2009.

RADHAKRISHNAN, S. Brahma Sutra: the philosophy of spiritual Life. London: Ruskin House; George Allen \& Unwin, 1960.

RAJU, P. T. Structural depths of indian thought. New York: State Univ. of New York Press, 1985. (Series in Philosophy).

SINGH, P. H. A history of the Carvakas. 2002. Available on: <http://evansexperientialism.freewebspace.com/Singh01.htm>. Access in: 18 ago. 2018.

SKRBINA, D. Panpsychism in the west. Cambridge, MA: MIT Press, 2005.

. Minds, objects, and relations: toward a dual-aspect ontology. In: (ed.). Mind that abides: panpsychism in the new millennium. Amsterdam: John Benjamins, 2009. p. 361-382.

SWAMI KRISHNANANDA. The Brihadaranyaka Upanishad. Rishikesh, Himalayas, India: The Divine Life Society, 1983. Available on: <http://www.swami-krishnananda. org/brdup/Brihadaranyaka_Upanishad.pdf>. Access in: 18 ago. 2018.

TONONI, G. An information integration theory of consciousness. BMC Neurosci, v. 5, n. 1, p. 42, 2004.

. Consciousness as integrated information: a provisional manifesto. Biol Bull, v. 215, n. 3, 216-242, 2008.

. Integrated information theory of consciousness: an updated account. Arch Ital Biol, v. 150, n. 4, p. 293-329, 2012.

TONONI, G.; KOCH, C. Consciousness: here, there but not everywhere. 2014. Available on: <http://arxiv.org/pdf/1405.7089v1>. Access in: 18 ago. 2018.

VIMAL, R. L. P. Proto-experiences and subjective experiences: classical and quantum concepts. J Integr Neurosci, v. 7, n. 1, p. 49-73, 2008.

. Meanings attributed to the term 'consciousness': an overview. J Consciousness Stud, v. 16, n. 5, p. 9-27, 2009a.

. Nāgārjuna's dependent co-origination and inherent existence, Buddhism, and extended dual-aspect monism. Vision Research Institute: Living Vision and Consciousness Research, v. 7, n. 2, p. 1-85, 2009b. Available on: <http://sites.google.com/site/rlpvimal/ Home/2018-Vimal-Coorigination-LVCR-7-2.pdf >. Access in: 18 ago. 2018.

Subjective experience aspect of consciousness part 1: integration of classical, quantum, and subquantum concepts. NeuroQuantology, v. 7, 3, p. 390-410, 2009c. 
Subjective experience aspect of consciousness part 2: integration of classical and quantum concepts for emergence hypothesis. NeuroQuantology, v. 7, n. 3, p. 411-434, 2009d.

Matching and selection of a specific subjective experience: conjugate matching and subjective experience. J Integr Neurosci, v. 9, n. 2, p. 193-251, 2010a.

. On the quest of defining consciousness. Mind Matter, v. 8, n. 1, p. 93-121, 2010 b.

. Towards a theory of everything part 1: introduction of consciousness in electromagnetic theory, special and general theory of relativity. NeuroQuantology, v. 8, n. 2, p. 206-230, 2010c.

. Towards a theory of everything part 2: introduction of consciousness in schrödinger equation and standard model using quantum physics. NeuroQuantology, v. 8, n. 3, p. 304-313, 2010d.

. Towards a theory of everything part 3: introduction of consciousness in loop quantum gravity and string theory and unification of experiences with fundamental forces. NeuroQuantology, v. 8, n. 4, p. 571-599, 2010e.

. Primal entity and scientific religions: science-religion unification through extended dual-aspect monism and its novel critiques. Vision Research Institute: Living Vision and Consciousness Research, v. 5, n. 3. 2012a. DOI: http://dx.doi.org/10.13140/2.1.1471.5847. Available on: <http://sites.google.com/site/rlpvimal/Home/2015-Vimal-Bringing-Science-andReligions-closer-DAM-5-3.pdf >. Access in: 18 ago. 2018.

. Scientific hinduism: bringing science and the spiritual aspect of hinduism closer via extended dual-aspect monism (Dvi-Pakșa Advaita). Vision Research Institute: Living Vision and Consciousness Research, v. 5, n. 4, 2012b. DOI: <http://dx.doi. org/10.13140/2.1.1982.0485. Available on: <http://sites.google.com/site/rlpvimal/ Home/2016-Vimal-Scientific-Hinduism-Bringing-Science-and-Hinduism-closer-eDAM5-4-book.pdf >. Access in: 18 ago. 2018.

Emergence in dual-aspect monism. In: PEREIRA JR., A.; LEHMANN, D. (ed.). The unity of mind, brain and world: Current Perspectives on a Science of Consciousness. Cambridge, UK: Cambridge University Press, 2013. p. 149-181.

. Biological naturalism in extended dual-aspect monism and conscious robots. Vision Research Institute: Living Vision and Consciousness Research, v. 7, n. 3, p. 1-23, 2015a. Available on: <http://sites.google.com/site/rlpvimal/Home/2015-Vimal-eDAMBN-LVCR-7-3.pdf $>$.

. Extended dual-aspect monism framework: criticisms addressed. Vision Research Institute: Living Vision and Consciousness Research, v. 7, n. 4, p. 1-26, 2015b. Available on: <http://sites.google.com/site/rlpvimal/Home/2015-Vimal-eDAM-CriticismsAddressed-LVCR-7-4.pdf >. Access in: 18 ago. 2018.

. The extended dual-aspect monism framework: segregation and integration of information, hard problem, and the critical test for the inseparability between aspects. 
Vision Research Institute: Living Vision and Consciousness Research, v. 7, n. 2, p. 1-174, 2015c. Available on: <http://sites.google.com/site/rlpvimal/Home/2016-Vimal-IIT-ineDAM-LVCR-4-1.pdf >. Access in: 18 ago. 2018.

. A Framework for neuroscience and consciousness: extended dual-aspect monism (Dvi-Pakșa Advaita). Vision Research Institute: Living Vision and Consciousness Research, v. 8, n. 4, p. 1-369, 2016a. Available on: <http://sites.google.com/site/rlpvimal/ Home/2016-Vimal-eDAM-DPA-LVCR-8-4.pdf >. Access in: 18 ago. 2018.

. Necessary and sufficient conditions for consciousness: extended dual-aspect monism framework. Vision Research Institute: Living Vision and Consciousness Research, v. 8, n. 5, p. 1-141, 2016b. Available on: <http://sites.google.com/site/rlpvimal/ Home/2016-Vimal-Necessary-sufficient-conditions-Conciousness-LVCR-8-5.pdf >. Access in: 18 ago. 2018.

Buddhism, hinduism, and science-based extended dual-aspect monism. Vision Research Institute: Living Vision and Consciousness Research, v. 9, n. 3, p. 1-622, 2017. Available on: <http://sites.google.com/site/rlpvimal/Home/2017-Vimal-Buddhism-andeDAM-Book-6.pdf >. Access in: 18 ago. 2018.

. Dependent co-origination and inherent existence: extended dual-aspect monism. Rev. Simbio-Logias: philosophical perspectives on meditation, v.10, n. 13, p. 160-210, 2018. Available on: <http://www.ibb.unesp.br/Home/Departamentos/Educacao/SimbioLogias/revistas/dependent_co-origination.pdf>; DOI: <http://dx.doi.org/10.32905/1983 3253.2018.13.10p160>.

. The extended dual-aspect monism framework: segregation and integration of information, and the critical test for the inseparability between aspects. NeuroQuantology, (accepted), 2019.

.; BHARDWAJ, S. Metaphysics, science, religion, and spirituality: bringing them closer via extended dual-aspect monism (Dvi-Pakșa Advaita). Vision Research Institute: Living Vision and Consciousness Research, v. 7, n. 6, p. 1-14, 2015. Available on: <http://sites.google.com/site/rlpvimal/Home/2015-Vimal-Spirituality-Science-CloserLVCR-7-6.pdf>. Access in: 18 ago. 2018.

. et al. Transgenerational epigenetic mechanisms, unconscious creativity, and sensory deprivation: semi-free will in the extended dual-aspect monism framework. Quantum Biosystems, v. 6, n. 1, p. 33-53, 2015.

.; POKORNY, J. M.; SMITH, V. C. Appearance of steadily viewed light. Vision Res., v. 27, n. 8, p. 1309-1318, 1987.

Recebido: 15/11/2018

Aceito: 15/11/2018 